\title{
Psychometric Properties of Turkish Version of Childhood Trauma Questionnaire among Adolescents with Gender Differences
}

\author{
Ayse Rezan Cecen-Erogul \\ Mugla University, Mugla, Turkey \\ Email: rezancecen@mu.edu.tr \\ Received July $8^{\text {th }}, 2012$; revised August $9^{\text {th }}, 2012$; accepted September $12^{\text {th }}, 2012$
}

\begin{abstract}
The aim of this study was to investigate the psychometric properties of the Turkish version of Childhood Trauma Questionnaire (CTQ) and its subscales among adolescents. The participants consisted of 1275 high school students $(14-19$ years) with a mean age of $16.33(\mathrm{SD}=1.01)$. The confirmatory factor analysis has revealed that CTQ has three subscale (physical abuse, emotional abuse, sexual abuse). Cronbach's alpha for the total scale was .91 , for physical abuse .84 , for emotional abuse .89 , for sexaul abuse .70 . The test-retest correlation coefficient for the total score $(\mathrm{n}=65)$ was .81 , for physical abuse .82 , for emotional abuse .80 , and sexual abuse .75 at 3 weeks indicating adequate reliability. Discriminant validity was satisfactory. The results of the study have shown that the Turkish version of CTQ psychometrically sound among high school students.
\end{abstract}

Keywords: Childhood Trauma Questionnaire; Validity; Reliability; Adolescents

\section{Introduction}

Child maltreatment is a serious threat to children's physical and psychological well-being (Damashek, Balachova, \& Bonner, 2011). Child maltreatment can result in significant longterm emotional and behavioral consequences, including posttraumatic stress disorder (e.g., Dubner \& Motta, 1999), aggression and anger (Shields, Cicchetti, \& Ryan, 1994; Korkut, 2011; Taner \& Gokler, 2004; Chapple, Tyler, \& Bersani, 2005), school difficulties (Erickson \& Egeland, 2002), depression (Boney-McCoy \& Finkelhor, 1996), social difficulties (Mannarino \& Cohen, 1996), criminal behavior (Gelles \& Straus, 1990), low life satisfaction (Korkut, 2012) and self esteem (Bagley, Bolitho, \& Mallick, 2001; Baldry, 2003; Durmuşoğlu \& Doğru, 2006; Korkut, 2012) and long-term health problems (Anda et al., 2006). Physical child abuse refers to acts that cause pain and permanent or temporary damage to the child's physical functions, such as bruises, burns, head injuries, fractures, or internal injuries (Kolko, 1996). Forms of physical abuse include hitting, kicking, burning with a cigarette, shaking by the hair, and strangling. The research have shown that physical abuse related to lack of social skills, low self esteem and anger management problems (Kaplan, Pelcovitz, \& Labruna, 1999; Nurcombe, 2000; Ystgaard, Hestetun, Loeb, \& Mehlum, 2004).

Abuse often causes a permanent physical injury, such as a scar or a neurological defect. Along with physical injuries, the following long-term affects may occur. The child adopts a violent behavioral pattern, or fear, anger, and distrust are provoked in the child (Lynch, 1988; Lewis, 1992; Kolko, 1996). Emotional abuse refers to cases where the child is criticized, terrorized, degraded, ridiculed, or isolated (Hart, Brassard, \& Karlson, 1996). Emotional abuse also occurs when the caregivers do not approve of or understand the child's activities or thoughts. Ac- cording to Hart, Brassard, \& Karlson, (1996) this kind of passive emotional disapproval of the child is the most harmful form of violence, because it is impossible for the child to develop a positive self-image. All types of abuse, such as corporal punishment, involve emotional abuse (Hart \& Brassard, 1991; Hart, Brassard, \& Karlson, 1996). Sexual abuse refers to physical abuse directed at the child's genitals and sexual characteristics, actual or attempted sexual intercourse, or any other sexual act that violates the child's physical integrity. Sexual abuse also involves leading children into sexual behavior that does not correspond to their age and developmental level, subjecting children to sexual stimuli, or using them as performers in obscene publications (Berliner \& Elliott, 1996). Epidemiological studies estimate that $27 \%$ of females and $16 \%$ of males experience at least one episode of sexual abuse during their childhood or adolescence (Timnik, 1985; Finkelhor, Hotaling, Lewis, \& Smith, 1990).

The Childhood Trauma Questionnaire (CTQ) is a self-report questionnaire that retrospectively assesses childhood abuse experiences among adolescents and adults. Items were constructed based on a review of the child abuse literature. In an early investigation of the responses of 286 drug- or alcohol-dependent patients to a 70-item version of the CTQ, Bernstein et al. (1994) reported that the results of yielded four factors: physical and emotional abuse, emotional neglect, sexual abuse, and physical neglect. In this study cronbach alpha changed between .79 - .94. In a later investigation of 398 adolescents admitted to an inpatient psychiatric hospital. Bernstein and colleagues (Bernstein, Ahluvalia, Pogge, \& Handelsman, 1997) reported five factor solution in which physical and emotional abuse split into separate factors. Confirmatory analyses of this five-factor solution have been conducted subsequently, with results supporting the appropriateness of this solution 
across adult substance abusers, adolescent psychiatric inpatients, and female HMO members (Bernstein \& Fink, 1998). Additionally, the CTQ has demonstrated convergent validity with both a clinician-rated interview of childhood abuse and therapists' ratings of abuse (Bernstein et al., 1997; Bernstein \& Fink, 1998; Fink, Bernstein, Handelsman, Foote, \& Lovejoy, 1995). Reliability of the CTQ is also encouraging. Test-retest reliabilities ranging from .79 to .86 over an average of 4 months suggest that the CTQ may be resistant to reporting biases because of transient mood states as well as longer term psychopathology. Moreover, the CTQ has demonstrated internal consistency reliability across a range of samples, with reliability coefficients ranging from a median of .66 for the physical neglect subscale to a median of .92 for the sexual abuse subscale (Bernstein \& Fink, 1998).

In Turkey Aslan \& Alpaslan (1999) adapted CTQ into Turkish among university students (age range between $17-25$; $\mathrm{n}=$ 744) but their sample did not include adolescents who attend high school. Aslan \& Alpaslan reported that the results of factor analysis yielded three factor solution (40-item): physical abuse (16-item), emotional abuse and neglect (19-item) and sexual abuse (5-item). The internal consistency of the scale for total scale .96 , for physical abuse .94 , for emotional abuse .95 and for sexual abuse .94. The criterion validity of the CTQ has shown significant correlations between CTQ and Beck Depresion Inventory, Spielberger Trait Anxiety Scale, Dissociative Experiences Scale, Toronto Alexithmia Scale.

In the light of literature, there is no research related to childhood trauma questionnaire validity and reliability on adolescent's population. Thus, the aim of this article is to investigate the psychometric properties of the Turkish version of Childhood Trauma Questionnaire (CTQ) and its subscales among adolescents. These properties include factor structure, internal consistency, test-retest reliability, inter-correlations of subscales and divergent and convergent validity. In addition on the same data gender differences were also investigated in respect of physical, emotional and sexual abuse.

\section{Method}

\section{Participants}

The study involved a community sample of 1275 adolescents (14 - 19 years) with a mean age of $16.33(\mathrm{SD}=1.01)$. The participants comprised 693 (54\%) girls and 582 (46\%) boys from different public high schools which represented middle socioeconomic status according to Adana, Gaziantep and Mardin Province National Education Directory statistic service. The participants composed of 501 (39\%) high school students from Adana, 324 (25\%) Gaziantep and 450 (35\%) Mardin. All students were volunteered for complete the questionnaires.

\section{Measurement}

\section{The Childhood Trauma Questionnaire}

(CTQ; Bernstain et al., 1994) CTQ is a screening tool to detect persons with experiences of childhood abuse and neglect. The original CTQ 70-item and the items are scored on five point scale from never (1) to everytime (5). The higher score indicating higher abuse experiences. Aslan \& Alpaslan (1999) adapted CTQ into Turkish on the sample of university students.
Aslan \& Alpaslan (1999) reported that Turkish version of CTQ has three factor that physical abuse (e.g., "I was punished with a belt, a board, a cord, or some other hard object"), emotional abuse and neglect (e.g., "People in my family called me things like 'stupid', 'lazy', or 'ugly'") and sexual abuse (e.g., "Someone tried to touch me in a sexual way, or tried to make me touch them") with the 40-item. They also reported the CTQ has good internal consistency (for all scale .90, for physical abuse .89 , emotional abuse and neglect .89, sexual abuse .90) and the criterion validity. In this study Aslan and Alpaslan 40item CTQ scale was tested among adolescents.

\section{State-Trait Anger Expression Inventory}

(STAXI; Spielberger et al., 1983) The STAXI which was developed by Spielberger, Jacobs, Russell, and Craine (1983) was used to determine anger levels expressed by people. The scale was translated and adapted into Turkish by Ozer (1994). The first 10 items of the scale measure trait anger (e.g., "I have a fiery temper") the other 24 items point out individuals' anger expression styles that anger in (e.g., "I boil inside but don't show it"), anger-out (e.g., "I control my urge to express my angry feelings") anger control (e.g., "I take a deep breath and relax"). The scale is a 4-point Likert type scale. Ozer (1994) reported that the scale has good validity and reliability. The internal consistency coefficients of the scale were found to be .79 for trait anger dimension, .84 for anger control, .78 for anger-out and .62 for anger control (Ozer, 1994). Higher scores on trait anger indicate higher anger levels; higher scores on the anger-in subscale indicate higher levels of suppressed anger; higher scores on the anger-out subscale indicate easier anger expression, and higher scores on the anger-control subscale indicate better anger control.

\section{Rosenberg Self-Esteem Scale}

(RSES; Rosenberg, 1965) The RSES was developed by Rosenberg (1965) and adapted into Turkish samples by Cuhadaroglu (1986). A 10-item (e.g., "I feel that I am a person of worth, at least on an equal plane with others") brief RSES refers to the global self-worth of individuals, rating on a 4-point liker type scale $(1=$ strongly disagree to $4=$ strongly agree $)$. Higher scores on the scale items indicate higher levels of self-esteem. Cuhadaroglu reported that the self-esteem scale is valid and reliable. The cronbach alpha of the scale .76 and test-retest reliability coefficients of .71 during a 4-week period on the Turkish version.

\section{The Satisfaction with Life Scale}

(SWLS; Diener et al., 1985) SWLS developed by Diener et al. (1985) and adapted to Turkish by Köker (1991) was used. The SWLS measures global life satisfaction and consists of 5 items (e.g., "The conditions of my life are excellent") of which the values are evaluated according to 7 scores $(1=$ strongly disagree, $7=$ strongly agree). According to the results of the validity and reliability study of the scale, the scale has good validity and reliability. Köker (1991) reported that an internal consistency coefficient for the Turkish version of this scale was .80 the test retest reliability was $r=.85$ and item total correlations varied between .71 and .80 . Higher scores of the scale indicate higher life satisfaction (Köker, 1991). 


\section{A. R. CECEN-EROGUL}

\section{Procedure}

For this study mainly permission was granted from Province of National Education Adana, Gaziantep, Mardin and approved by the Regional Educational Research Committee for research ethics in schools. The schools which represent middle SES in the sample were selected basis on Ministry of National Education statistics. Additional permission was granted from the public school principals. The consent form was declared and the purpose of the study was explained to all students in the classroom setting. It was observed that all students accepted to be volunteer for this study. All students in the classroom completed the questionnaire, on a grade basis. The instructions were read to all children. Children and adolescents were supervised during administration of the questionnaire. Assistance was also available to participants however answers were not influenced by the examiner.

\section{Statistical Analyses}

Data from the sample were used to examine factor structure previously identified three factors by Aslan and Alpaslan (1999), internal consistency, test-retest reliability, convergent and divergent validity on the sample of high school students. In order to examine the factor structure, confirmatory factor analysis with USLMV estimation using Mplus 5.21 (Muthen \& Muthen, 2009) was conducted. To investigate sex differences ANOVAs were carried on the data.

\section{Findings}

Multivariate tests of normality using Mplus revealed evidence of marked positive skew and kurtosis in the data, with the majority of responses clustering around low frequencies of childhood trauma experiences. In cases where data violate normality, estimation methods such as maximum likelihood are unsuitable as they rely on the normality assumption. Therefore, the data were examined using the ULSMV estimation method, which takes into account deviations from normality (Muthen \& Muthen, 2009). Based on Aslan \& Alpasan (1999) a three factor structure (physical abuse, emotional abuse and neglect, and sexual abuse) was hypothesized analysis applied on the community sample data. Generally, TLI, and CFI values of .90 or above reflect good fit, and values between .80 and .90 represent adequate-to-good fit (Hu \& Bentler, 1999). An RMSEA of about .05 reflects a close fit of the model in relation to its degrees of freedom, whereas values as high as .08 reflect a reasonable error of approximation (Byrne, 1998).

Confirmatory factor analysis applied to 40 item questionnaire for three factor models and 5 item (11-14-20-27-28) deleted because of the low factor loadings (below .30). Thus, after deleted five items, two models were tested on 35 item. In the first model only a three factor model and in the second model three factor second order model were tested. Both results of models produce the same factor loadings and value of same fit indices. Thus, three factor second order model was accepted. By using ULSMV, consistent with Aslan and Alpaslan (1999), with all of the following cutoff criteria for fit indices outlined by Muthen $\&$ Muthen (2009) in either the "good" $\left(\chi^{2}=1270.407 ; d f=557\right.$; $p<.000)$ Comparative Fit Index (CFI) .925, Tucker Lewis index (TLI) .920 or "fair" Root Mean Squared Error of Approximation (RMSEA) .04 for the current sample. The results of confirmatory factor analyses provided support for the con- struct validity of the CTQ subscales, consisting of three clear content factors relating to physical abuse, emotional abuse and social abuse.

Standardized factor loadings on the predicted three factors are presented in Table 1. The factor loadings range for physical

Table 1.

Standardized factor loadings on the predicted four factors.

\begin{tabular}{|c|c|c|c|c|}
\hline \multirow{2}{*}{ Predicted Factors } & & \multicolumn{3}{|c|}{ Factor loadings } \\
\hline & & 1 & 2 & 3 \\
\hline \multirow[t]{12}{*}{ Physical Abuse } & 1 & .65 & & \\
\hline & 3 & .55 & & \\
\hline & 5 & .71 & & \\
\hline & 6 & .66 & & \\
\hline & 9 & .69 & & \\
\hline & 16 & .66 & & \\
\hline & 18 & .72 & & \\
\hline & 21 & .70 & & \\
\hline & 24 & .69 & & \\
\hline & 25 & .65 & & \\
\hline & 30 & .83 & & \\
\hline & 33 & .62 & & \\
\hline \multicolumn{5}{|l|}{ Emotional Abuse } \\
\hline & 2 & & .57 & \\
\hline & 4 & & .66 & \\
\hline & 7 & & .77 & \\
\hline & 8 & & .69 & \\
\hline & 10 & & .60 & \\
\hline & 12 & & .79 & \\
\hline & 13 & & .70 & \\
\hline & 15 & & .65 & \\
\hline & 19 & & .41 & \\
\hline & 22 & & .66 & \\
\hline & 23 & & .48 & \\
\hline & 26 & & .53 & \\
\hline & 32 & & .69 & \\
\hline & 35 & & .75 & \\
\hline & 36 & & .58 & \\
\hline & 37 & & .59 & \\
\hline & 38 & & .76 & \\
\hline & 40 & & .77 & \\
\hline \multicolumn{5}{|l|}{ Sexual Abuse } \\
\hline & 17 & & & .63 \\
\hline & 29 & & & .73 \\
\hline & 31 & & & .77 \\
\hline & 34 & & & .77 \\
\hline & 39 & & & .85 \\
\hline
\end{tabular}


abuse from .55 to .83 , for emotional abuse .41 to .79 , for sexual abuse .63 to .85 . All subscale factor loadings are higher than .40. Standardized factor loadings for the higher order model are shown in Table 2. As shown in Table 2, the standardized factor loadings of each first-order factor on the higher order factor for the model were .89 for physical abuse, .73 for emotional abuse, .63 for sexaul abuse. The intercorrelations between first order factors are; for physical and emotional abuse and neglect .65, for physical and sexual abuse .56 and for emotional abuse and neglect and sexual abuse .45 (See Table 2). The percentage of variance in the first-order factors that could be explained by the higher order factor ranged from $40 \%$ for sexual abuse to $79 \%$ for physical abuse.

\section{Internal Consistency and Test-Retest Reliability}

Internal consistency was calculated using the total community sample of 1275 children and adolescents. Cronbach's alpha coefficient for the total scale was .91 indicating a high degree of homogeneity among items comprising the scale. Internal consistency of the subscales was also high, with coefficient alphas of .84 for physical abuse, .89 for emotional abuse, .70 for sexual abuse.

Test-retest reliability was demonstrated using a subsample of 65 adolescents who were reassessed 3 weeks after the initial administration of the questionnaire. The test-retest correlation coefficient for the total score was .81 , for physical abuse .82 , for emotional abuse .80 , and sexual abuse .75 at 3 weeks indicating adequate reliability. Coefficients were high across all subscales and the total score indicating that the scale has good temporal stability.

\section{Relationship with Trait-Anger Expression Styles, Self-Esteem and Life Satisfaction Scales}

The convergent and discriminant validity of the CTQ and it's subscales was examined using Pearson's correlations with self-report measures of trait anger and anger expression styles, self esteem and life satisfaction (Table 3). The mean score on the physical abuse was $21.18(\mathrm{SD}=.50 ; \mathrm{n}=450)$, emotional abuse was $35.39(\mathrm{SD}=9.95, \mathrm{n}=450)$, sexual abuse was 6.15 $(\mathrm{SD}=2.36, \mathrm{n}=450)$ trait anger was $26.42(\mathrm{SD}=5.88, \mathrm{n}=450)$ while on the anger in was $17.97(\mathrm{SD}=4.25, \mathrm{n}=450)$, anger out was $17.77(\mathrm{SD}=4.99, \mathrm{n}=450)$, anger control was $20.57(\mathrm{SD}=$ $4.90, \mathrm{n}=450)$, self esteem was $29.01(\mathrm{SD}=5.17, \mathrm{n}=550)$, life satisfaction was $21.0(\mathrm{SD}=5.49, \mathrm{n}=550)$. All correlations were significant in the expected direction. Theoretically it would be expected positive correlations between physical, emotional, sexual abuse and trait anger, anger in anger out; negative correlations between the physical, emotional, sexual abuse and anger control, self esteem and life satisfaction.

\section{Gender Differences}

To examine gender differences in scores on the CTQ, ANOVAs were carried out for each subscale and the two total scores. A Bonferroni correction was applied to avoid inflation of the type I error rate. Means and SD for each (sub) scale are presented in Table 4. Significant main effects for gender were found for the emotional abuse $F(1,1275)=13.81, p<.001$; sexual abuse, $F(1,1275)=10.31, p<.001$ except physical abuse $F(1,1275)=2.15, p>.05$.

The means of the CTQ subscale scores indicating boys reported more childhood physical, emotional and sexual abuse

Table 2.

Standardized intercorrelations between first-order factors and statistical relationships between first-order and higher order factors.

\begin{tabular}{cccccc}
\hline Factor & 1 & 2 & 3 & $\begin{array}{c}\text { Standardized loading of first order } \\
\text { factor on higher order }\end{array}$ & $\begin{array}{c}\text { \% of variance explained by } \\
\text { higher order factor }\end{array}$ \\
\hline 1. PA & - & & .89 & .79 \\
2. EA and Neg. & .65 & - & .73 & .63 & .53 \\
4. SA & .56 & .45 & - & .40 & .40 \\
\hline
\end{tabular}

Note: PA = Physical abuse; EA and Neg. = Emotional abuse and Neglect; SA = Sexual abuse.

Table 3.

The pearson correlations results between the variables.

\begin{tabular}{|c|c|c|c|c|c|c|c|c|c|c|}
\hline & CTQ & PA & EAN & SA & TA & AI & $\mathrm{AO}$ & $\mathrm{AC}$ & SE & LS \\
\hline CTQ (total) & - & & & & & & & & & \\
\hline Physical Abuse & $.77^{*}$ & & & & & & & & & \\
\hline Emot. Abuse-Neglect & $.82^{*}$ & $.46^{*}$ & & & & & & & & \\
\hline Sexual Abuse & $.44^{*}$ & $.23^{*}$ & $.28^{*}$ & & & & & & & \\
\hline Trait Anger & $.41^{*}$ & $.41^{*}$ & $.31 .^{*}$ & $.19^{*}$ & & & & & & \\
\hline Anger In & $.27^{*}$ & $.30^{*}$ & $.18^{*}$ & $.10^{*}$ & $-.39^{*}$ & & & & & \\
\hline Anger Out & $.23^{*}$ & $.27^{*}$ & $.12^{*}$ & $.21^{*}$ & $.54^{*}$ & $.52^{*}$ & & & & \\
\hline Anger Control & $-23^{*}$ & $-.18^{*}$ & $-.20^{*}$ & $-.20^{*}$ & $-.34^{*}$ & $-.12^{*}$ & $-.43^{*}$ & & & \\
\hline Self-esteem & $-.38^{*}$ & $-.32^{*}$ & $-.49^{*}$ & $-.49^{*}$ & $-.35^{*}$ & $-.21^{*}$ & $.18^{*}$ & $.14^{*}$ & & \\
\hline Life Satisfaction & $-.53^{*}$ & $-.32^{*}$ & $-.34^{*}$ & $-.34^{*}$ & $-.23^{*}$ & $-.21^{*}$ & $-.19^{*}$ & $.23^{*}$ & $.40^{*}$ & - \\
\hline
\end{tabular}

Note: ${ }^{*} p<.001$. 


\section{A. R. CECEN-EROGUL}

Table 4.

Gender differences on total CTQ and its subscales scores.

\begin{tabular}{|c|c|c|c|c|c|c|c|}
\hline CTQ and Subscales & Gender & $\mathrm{N}$ & $\mathrm{X}$ & $S D$ & $d f$ & $\mathrm{~F}$ & $p$ \\
\hline \multirow{3}{*}{ Physical Abuse } & Girls & 693 & 18.80 & 6.32 & 1 & \multirow{3}{*}{.062} & \multirow{3}{*}{.804} \\
\hline & Boys & 582 & 18.71 & 6.13 & 12 & & \\
\hline & Total & 1275 & 18.76 & 6.23 & 1274 & & \\
\hline \multirow{3}{*}{$\begin{array}{l}\text { Emotional Abuse } \\
\text { and Neglect }\end{array}$} & Girls & 693 & 32.68 & 11.93 & 1 & \multirow{3}{*}{4.948} & \multirow{3}{*}{.026} \\
\hline & Boys & 582 & 34.13 & 11.24 & 12 & & \\
\hline & Total & 1275 & 33.34 & 11.64 & 1274 & & \\
\hline \multirow{3}{*}{ Sexual Abuse } & Girls & 693 & 5.28 & 2.04 & 1 & \multirow{3}{*}{8.331} & \multirow{3}{*}{.004} \\
\hline & Boys & 582 & 5.61 & 2.09 & 12 & & \\
\hline & Total & 1275 & 5.43 & 2.07 & 1274 & & \\
\hline \multirow{3}{*}{ CTQ (total) } & Girls & 693 & 56.76 & 17.10 & 1 & \multirow{3}{*}{3.337} & \multirow{3}{*}{.068} \\
\hline & Boys & 582 & 58.47 & 15.92 & 12 & & \\
\hline & Total & 1275 & 57.54 & 16.59 & 1274 & & \\
\hline
\end{tabular}

Note: ${ }^{*} p<.05$.

than girls. ANOVA results shown that there were significant effect on childhood emotional and sexual abuse according to gender, but there was not significant effect on physical abuse according to gender.

\section{Discussion}

The aim of this study was to investigate the psychometric properties of the CTQ among adolescents. To investigate validity and reliability of CTQ, data was collected from 9th, 10th, 11 th to 12 th grade students.

The results of the confirmatory factor analysis has confirmed that the 35-item CTQ has three factor as in Aslan and Alpaslan (1999) study. In this study findings indicated that fit indices were satisfactory and three-factor structure of the CTQ was supported in the current adolescents sample. This results indicated that the factor structure of the CTQ in the current sample was very similar to the earlier study results using the CTQ (Aslan \& Alpaslan, 1999). All 35-item factor loadings were .40 and above. Furthermore, intercorrelations of the three subscales provide evidence that physical abuse, emotional abuse and sexual abuse have a common core but are relatively different constructs. The sexual abuse factor had the lowest intercorrelation and the lowest factor loading in this sample. This is consistent with previous findings that the sexual abuse factor was, found to display the lowest intercorelation and lowest factor loadings (Aslan \& Alpaslan, 1999).

The results of internal consistency and test-retest reliability of the CTQ was satisfactory. Internal consistency of CTQ displayed a high degree of homogeneity among items comprising the scale. Test-retest reliability with a subsample of adolescents demonstrated good test-retest reliability similarly, the stability of scores on individual subscales was also satisfactory at three weeks after initial testing. This indicates that the questionnaire is a stable measure of CTQ. The CTQ and its subscales test-retest reliability was comparable to earlier results for this time period (Aslan \& Alpaslan, 1999; Bernstein \& Fink, 1998). The convergent and divergent validity of the CTQ was satis- factory. As expected the self-esteem scale, satisfaction with life scale and anger control subscale were negatively associated with all CTQ subscales and total CTQ scores. In addition as expected direction trait anger, anger anger in and anger out subscales were positively associated with all CTQ subscales and total CTQ scores. Specifically, the correlations between physical abuse, emotional abuse and sexual abuse and total scores and the self-esteem, satisfaction with life, anger expression styles and trait anger measures were all moderate to relatively high. All these results can be evidence for criterion validity of CTQ.

Finally, sex differences in mean scores were investigated on the current sample. The total CTQ and its subscales (physical, emotional, sexual abuse) scores were higher among boys than girls. Although there were no significant overall difference on the CTQ and on the physical abuse scores between males and females, there were significant effect of gender on emotional and sexual abuse subscales scores.

The result has shown that no significant physical abuse difference according to the gender. This result is consistent with some previous studies in the literature (Bulut-Ateş \& ÇeçenEroğul, 2011; Kalkan \& Karadeniz-Özbek, 2011; Kaya \& Çeçen-Eroğul, 2011; Yılmaz-Irmak, 2008) but not consistent some studies that there is a significant difference according to gender (Bekçi, 2006; Horton \& Cruise, 2001; Karaca, 2001; Yenibaş, 2002; Ziyalar, 1993). There were significant differences on the emotional and sexual abuse scores that the male students have higher scores on this subscales. This results support previous research findings in our country (Aslan \& Alpaslan, 1999; Bulut-Ateş \& Çeçen-Eroğul, 2011; Kalkan \& Karadeniz-Özbek, 2011; Kaya \& Çeçen-Eroğul, 2011) but not support the general abuse literature in western culture, especially the research reported that sexual abuse prevelans is higher among girls than boys (Bernstein et al., 1994; Jacobson \& Richardson, 1987). The difference might be explained by cultural differences, in collectivist culture as in our country, especially families tend to more protective to girls than boys. As a reality both gender can exposure to the abuse, but further 
research is needed to clarify these findings that why boys reports more childhood trauma experiences than girls.

As a results of the study, the Turkish version of CTQ has good validity and reliability for adolescents population. The CTQ for adolescents can be used for investigating childhood trauma experiences. This study has some limitations. The limitation of this study is that the factor structure and psychometric properties of the measure were not evaluated in a clinical group. It would be useful to assess its temporal stability as well as to further evaluate its psychometric properties using more diverse Turkish populations including clinical samples.

In conclusion, the Turkish version of childhood trauma questionnaire can be used confidently on adolescents population to assess childhood trauma experiences.

\section{REFERENCES}

Anda, R. F., Felitti, V. J., Bremmer, J. D., Walker, J. D., Whitfield, C., $\&$ Perry, B. D. (2006). The enduring effects of abuse and related adverse experiences in childhood. European Archives of Psychiatry \& Clinical Neuroscience, 256, 174-186.

doi:10.1007/s00406-005-0624-4

Aslan, S. H., \& Alparslan, N. (1999). The validity, reliability and factor structure of the childhood trauma questionnaire among a group of university students. Turkish Journal of Psychiatry, 10, 275-285.

Bagley, C., Bertrand, L. Bolitho, F., \& Mallick, K. (2001). Discrepant parentadolescent views on family functioning: Predictors of pooreer self-esteem and problems of emotion and behaviour in british and canadian adolescents. Journal of Comparative Family Studies, 32, 393-403.

Baldry, A. C. (2003). Bullying in schools and exposure to domestic violence. Child Abuse and Neglect, 27, 713-732. doi:10.1016/S0145-2134(03)00114-5

Bekçi, B. (2006). The relation between domestic maltreatment and anger triggers among secondary school adolescents. Unpublished master thesis, Istanbul: Istanbul University.

Berliner, L., \& Elliott, D. (1996). Sexual abuse of children. In J. Briere, L. Berliner, J. Bulkley, C. Jenny, \& T. Reid (Eds.), The APSAC Handbook of Child Maltreatment (pp. 51-71). Thousand Oaks, CA: Sage.

Bernstein, D. P., Fink, L., Handelsman, L., Foote, J., Lovejov, M., Wenzel, K. et al. (1994). Initial reliability and validity of a new retrospective measure of child abuse and neglect. American Journal of Psychiatry, 151, 1132-1136.

Bernstein, D. P., Ahluvalia, T., Pogge, D., \& Handelsman, L. (1997). Validity of the childhood trauma questionnaire in an adolescent psychiatric population. Journal of the American Academy of Child \& Adolescent Psychiatry, 36, 340-348. doi:10.1097/00004583-199703000-00012

Bernstein, D. P., \& Fink, L. (1998). Childhood Trauma Questionnaire: A retrospective self-report manual. San Antonio, TX: The Psychological Corporation.

Boney-McCoy, S., \& Finkelhor, D. (1996). Is youth victimization related to trauma symptoms and depression after controlling for prior symptoms and family relationships? A longitudinal, prospective study. Journal of Consulting and Clinical Psychology, 64, 14061416. doi:10.1037/0022-006X.64.6.1406

Bulut-Ateş, F., \& Cecen Erogul, A. R. (2011). Perception of marital conflict and childhood maltreatment experince in predicting delinquent behaviours among adolescents. 11th National Psychological Counseling and Guidance Congress Proceedings, Selçuk, 3-5 October 2011.

Chapple, C. L., Tyler, K., \& Bersani, B. E. (2005). Child neglect and adolescents violence: Examining the effects of self-control and peer rejection. Violence and Victims, 1, 39-54.

Çuhadaroğlu Ç. F. (1985). Self-esteem among adolescents. 21st National Psychiatry and Neurology Congress Proceedings. Adana: Cukurova University.
Çuhadaroğlu, F. (1986) Self-esteem among adolescents. Unpublished master thesis, Ankara: Hacettepe University.

Damashek, A., Balachova, T., \& Bonner, B. (2011). Training competent psychologists in the field of child maltreatmant. Journal of Clinical Psychology, 67, 752-757. doi:10.1002/jclp.20803

Diener, E., Emmons, R. A., Larsen, R. J., \& Griffin, S. (1985). The satisfaction with life scale. Journal of Personality Assessment, 49, 71-75. doi:10.1207/s15327752jpa4901 13

Dubner, A. E., \& Motta, R. W. (1999). Sexually and physically abused foster care children and posttraumatic stress disorder. Journal of Consulting and Clinical Psychology, 67, 367-373. doi: 10.1037/0022-006X.67.3.367

Durmuşoğlu, N., \& Doğru, S. S. Y. (2006). Çocukluk örseleyici yaşantılarının ergenlikteki yakın ilişkilerde bireye etkisinin incelenmesi. Selçuk Üniversitesi Sosyal Bilimler Enstitü Dergisi, 15, 237-246.

Erickson, M. F., \& Egeland, B. (2002). Child neglect. In J. E. B. Myers, L. Berliner, J. Briere, C. T. Hendrix, C. Jenny, \& T. A. Reid (Eds.), The APSAC handbook on child maltreatment (2nd ed., pp. 3-20). Thousand Oaks, CA: Sage.

Fink, L., Bernstein, D., Handelsman, L., Foote, J., \& Lovejoy, M. (1995). Initial reliability and validity of the Childhood Trauma Interview: A new multidimensional measure of childhood interpersonal trauma. American Journal of Psychiatry, 152, 1329-1335.

Finkelhor, D., Hotaling, G., Lewis, I. A., \& Smith, C. (1990). Sexual abuse in a national survey of adult men and women: Prevalence, charecteristics and risk factors. Child Abuse and Neglect, 14, 19-28. doi:10.1016/0145-2134(90)90077-7

Gelles, R. J., \& Straus, M. A. (1990). The medical and psychological costs of family violence. In M. A. Straus, \& R. J. Gelles (Eds.), Physical violence in American families: Risk factors and adaptations to violence in 8145 families (pp. 425-430). New Brunswick, NJ: Transaction.

Hart, S., \& Brassard, M. (1991). Psychological maltreatment: Progress achieved. Development and Psychopathology, 3, 61-70. doi:10.1017/S0954579400005095

Hart, S., Brassard, M., \& Karlson, H. (1996). Psychological maltreatment. In J. Briere, L. Berliner, J. Bulkley, C. Jenny, \& T. Reid (Eds.), The APSAC handbook on child maltreatment (pp. 72-89). Thousand Oaks, CA: Sage.

Horton, C. B., \& Cruise, T. K. (2001). Child abuse and neglect, the school's responce. New York: The Guilford Press.

Kalkan, M., \& Karadeniz-Özbek, S. (2011). Çocukluk çağı örselenme yaşantıları ergenlerdeki flört kaygısını yordar mı? Çocuk ve Gençlik Ruh Să̆llğ Dergisi, 18, 35-44.

Kaplan, S., Pelcovitz, D., \& Labruna, V. (1999). Child and adolescent abuse and neglect research: A review of the past 10 years. Part I: Physical and emotional abuse and neglect. Journal of the American Academy of Child and Adolescent Psychiatry, 38, 1214-1222. doi:10.1097/00004583-199910000-00009

Kaya, İ., \& Cecen-Erogul, A. R. (2011). The role of family functions as the predictors of childhood maltreatment experinces among adolescents. 11th National Psychological Counseling and Guidance Congress Proceedings, Selçuk, 3-5 October 2011.

Köker, S. (1991). The examination of life satisfaction among adolescents who have problems and not problems. Unpublished master thesis. Ankara: Ankara University Social Science Institute.

Kolko, D. (1996). Child physical abuse. In J. Briere, L. Berliner, J. Bulkley, C. Jenny, \& T. Reid (Eds.). The APSAC handbook on child maltreatment (pp. 21-50). Thousand Oaks, CA: Sage.

Lewis, D. (1992). From abuse to violence: Psychophysiological conesquences of maltreatment. Journal of American Academy of Child and Adolescent Psychiatry, 31, 383-391. doi:10.1097/00004583-199205000-00001

Lynch, M. (1988). The consequences of child abuse. In K. Browne, C. Davies, \& P. Stratton (Eds.). Early prediction and prevention of child abuse (pp. 203-211). Chichester: Wiley.

Mannarino, A. P., \& Cohen, J. A. (1996). Abuse-related attributions and perceptions, general attributions,and locus of control in sexually abused girls. Journal of Interpersonal Violence, 11, 162-180. doi: $10.1177 / 088626096011002002$

Muthen, B., \& Muthen, L. (2009). Mplus 5.21 Base program and 


\section{A. R. CECEN-EROGUL}

combination add-on. Mplus user's guide.

Nurcombe B. (2000). Child sexual abuse I: Psychopathology. Australian and New Zealand Journal of Psychiatry, 34, 85-91. doi:10.1046/j.1440-1614.2000.00642.x

Özer, A. K. (1994). Sürekli öfke (SL-ÖFKE) ve öfke ifade tarzı (ÖFKE-TARZ) ölçekleri ön çalışması. Türk Psikoloji Dergisi, 9, 2635 .

Rosenberg, M. (1965). Society and the adolescent self-image. Princeton, NJ: Princeton University Press.

Shields, A. M., Cicchetti, D., \& Ryan, R. M. (1994). The development of emotional and behavioral self regulation and social competence among maltreated school-age children. Development and Psychopathology, 6, 57-75.

Spielberger, C. D. (1988). State-trait anger expression inventory. Odessa, FL: Psychological Assessment Resources.
Spielberger, C. D., Jacobs, G., Russell, S., \& Crane, R. S. (1983). Assessment of anger: The State-Trait Anger Scale. In J. N. Butcher, \& C. D. Spielberger (Eds.), Advances in personality assessment (pp. 161-189). Hillsdale, NJ: Lawrence Erlbaum Associates.

Timnik, L. (1985). The sexually abused children. Child Abuse \& Neglect, 2, 345-356

Yenibaş, R. (2002). The relationship between domestic maltreatment and neglect and hopelessness among adolescents. Unpublished master thesis, Istanbul: Marmara University.

Yilmaz-Irmak, T. (2008). The prevalence of child abuse and neglect and resilience. Unpublished master thesis, İzmir: Ege University.

Ystgaard, M., Hestetun, I., Loeb, M., \& Mehlum, L. (2004). Is there a spesific relationship between childhood sexual and physical abuse and repeated suicidal behaviour? Child Abuse and Neglect, 28, 863875. doi:10.1016/j.chiabu.2004.01.009 